Part II explores the nature of interactive reading and suggests reasons why second language readers may fail to process text interactively and so read badly. Throughout there is a studied effort to avoid simplistic explanation. Eskey, for instance, argues convincingly for careful attention to be paid to the development of decoding skills, avoiding the danger of an over-emphasis on the higher-level skills. And Carrell points to the deleterious effects of unidirectional processing of text. All the contributors are concerned to show that the new emphasis on top-down processing should not lead to a neglect of bottomup strategies or skills.

Those with an interest in research will find the investigations in Part III of particular interest. In each case, the empirical studies have been concerned with complex questions, so it is not surprising that the findings are not generally conclusive. Nevertheless, they do provide evidence that should be taken seriously. It seems, for instance, that the ways readers conceptualise the reading process are directly related to their different types of reading performance. Researchers will find the clear accounts of the research most valuable in setting up and defining their own projects, and teachers will be challenged to adapt their own practice in the light of these chapters.

Part IV, which is concerned with the theoretical and practical implications of seeing second language reading as interactive, presents a complex picture. As in the rest of the book, there is a laudable avoidance of simplistic answers. However, one would have expected this part to have offered more to the teacher. Carrell succeeds in making specific pedagogic suggestions without compromising her academic integrity, but the other two chapters rather scant the classroom. Many would welcome articles based on them, written for FORUM or ELT Journal with these particular needs in mind. The pedagogic implications noted by the writers of Part IV should be given the widest possible coverage.

Taken as a whole, this volume is a splendid contribution to applied linguistics. Reading researchers will find it invaluable. Every postgraduate course in reading should make it a core text. And teachers who are prepared to make the effort will mine it to their own enrichment and the profit of their classes.

\title{
E Ridge
}

\section{Pat Pattison}

Developing communication skills: A practical handbook for language teachers, with examples in English, French and German. Cambridge: Cambridge University Press, 1987. (272 pp.) 
Much has been written in recent times about the communicative approach to language teaching, most of it focusing on the rationale for CLT. As the decade nears its end, the majority of second and foreign language teachers appear to need no further convincing of the merits of this approach, but inevitably there are still many unanswered questions regarding its implementation in the classroom. For this reason, Pattison's publication should be widely welcomed.

We are told very little about the author except that he (she?) has considerable experience of second language teaching at various levels in Europe and Canada, and of teacher training in Great Britain and the Netherlands. The feedback Pattison gained from questionnaires used to determine learner and teacher priorities in the L2 classroom stressed the importance of, and need for, the development of especially oral skills, both receptive and productive. In response to this need, he set out to describe activities suitable for general language courses in schools and which take into account differences in teaching conditions and target groups.

His aim was to provide activities which were:

* effective: that is, they improved learner motivation and performance in practice

* efficient: in terms of the time needed to prepare and to use them in class

* flexible: in terms of the number of ways in which, or levels at which, the activity could be practised (p. 3).

He was further influenced by the firm belief that there is "... a gradation, a difference in the degree or depth of communicative force present in language exercises ... rather than a division between types of exercise which are seen as inherently non-communicative or inherently communicative. We can move exercises or activities of any kind closer to the communicative end of the spectrum ... by increasing the learners' sense of involvement in what they are hearing and saying" (p. 9). Many of his practical suggestions are based on a careful comparison of the kind of language used inside and outside the classroom in terms of what is said, why it is said, who participates in the communication act, how communication takes place and what the results of communication are.

The book has two sections. Part one discusses the problems of implementing CLT. The author immediately addresses the issues of using group work effectively, minimizing the use of the mother tongue, responding to learners' errors (some excellent practical ideas are offered), the role of the textbook and the role played by the learners' age, ability and different learning styles. From 
this discussion it is clear that Pattison has realistically anticipated the problems teachers are likely to encounter.

The second section, which makes up the bulk of the book, comprises seven sets of learning activities. To ensure the teacher's optimum use of these, a separate section is devoted to an explanation of their layout, aims, choice of material, choice of classroom seating arrangements, etc. Each set of activities is preceded by an introduction which provides an overview of all the activities contained in that set. The activities have been classified as follows:

* Questions and answers

* Dialogues and role-plays

* Matching activities

* Communication strategies

* Pictures and picture stories

* Puzzles and problems

* Discussions and decisions

The activities are described in three stages to show how they can be used in different ways, moving from receptive, teacher-centered or controlled practice to productive, learner-centered or independent practice. These pages are packed with genuinely practical and realistic ideas, presented in. English, French and German. Many of them are accompanied by illustrations, maps and diagrams which may be photocopied by L2 teachers for their personal use.

Particularly useful for anyone looking for interesting materials or just new ideas is the fact that all the sections are cross-referenced, and there are detailed indexes and booklists so that teachers can find what they need easily. There are separate indexes for language structures, functions, situations and topics, as well as a general index which lists activities for such purposes as receptive practice, reading and writing, cultural content, etc.

I was attracted by the book's claim to be "a practical handbook for language teachers" and can truthfully report that it lives up to this claim. I was impressed by its layout and by the scope, variety and originality of the activities it contains. Even those already familiar to some teachers have been presented in a different format with indications of how they can be adapted for different purposes. The indexes are truly helpful and the busy teacher will have no difficulty finding activities to fit in with the aims, both general and specific, 
of most of his $\mathrm{L} 2$ lessons. The universal validity of a communicative approach to $\mathrm{L} 2$ teaching is underlined by the fact that these activities appear to work equally well whether the target language is French, German or English.

I recently reviewed Rivers's Interactive language teaching (Cambridge University Press, 1987), which also contains much practical guidance for the L2 teacher. While Pattison's book does not pretend to have the same scope (mainly because of its emphasis on oral skills), it offers more practical material at all levels, from beginner to advanced. It is full of ideas ready for use, and for that reason I can heartily recommend it to second and foreign language teachers anywhere.

\section{J.J. Swartz}

